\title{
On the Orientation of Fractures with Transpressional and Transtensional Wrenches in Pre-Existing Faults
}

\author{
Shuping Chen ${ }^{1,2^{*}}$ \\ ${ }^{1}$ State Key Laboratory of Petroleum Resources and Prospecting, China University of Petroleum (Beijing), Beijing, China \\ ${ }^{2}$ College of Geosciences, China University of Petroleum, Beijing, China \\ Email: *csp21c@163.com
}

How to cite this paper: Chen, S.P. (2020) On the Orientation of Fractures with Transpressional and Transtensional Wrenches in Pre-Existing Faults. World Journal of Mechanics, 10, 199-209.

https://doi.org/10.4236/wjm.2020.1011014

Received: August 23, 2020

Accepted: November 7, 2020

Published: November 10, 2020

Copyright $\odot 2020$ by author(s) and Scientific Research Publishing Inc. This work is licensed under the Creative Commons Attribution International License (CC BY 4.0).

http://creativecommons.org/licenses/by/4.0/ (c) (i) Open Access

\begin{abstract}
The orientation of fractures with transpressional and transtensional wrenches in pre-existing faults has not been quantitatively determined. Based on Coulomb failure criterion and Byerlee's frictional sliding criterion, this paper has indicated quantitative geometric relationships between the pre-existing fault and the local induced principal stress axes caused by the rejuvenation of the pre-existing fault. For a hidden pre-existing fault with some cohesion, the angles between the local induced principal stress axes and the pre-existing fault quantitatively vary with the applied stress and the cohesion coefficient, the ratio of the thickness of the cover layer to the thickness of the whole wrench body, whether transpressional or transtensional wrenches occur. For a surface pre-existing fault with zero cohesion, the angles between the pre-existing fault and the local induced principal stress axes are related to the rock inner frictional angle regardless of both the applied stress and the cohesion coefficient where transpressional wrenches occur, and the local induced maximum principal stress axis is identical with the applied maximum principal stress axis where transtensional wrenches occur. Therefore, the geometric relationships between the pre-existing faults and their related fractures are defined, because the local induced principal stress axes determine the directions of the related fractures. The results can be applied to pre-existing weak fabrics. They can help to understand and analyze wrench structures in outcrops or subsurface areas. They are of significance in petroleum exploration.
\end{abstract}

\section{Keywords}

Wrench, Pre-Existing Fault, Wrench Related Fracture, Geometric Relationship 


\section{Introduction}

Wrench zones and their related structures were common both in outcrops and in oil-bearing areas [1]-[11]. They are of significance in exploration of oil and gas [12] [13] [14] [15].

There are three types of strike-slip faults: pure strike-slip, transtensional and transpressional wrenches (Figure 1) [16]. The earliest physical modeling of a wrench zone was conducted in a mud model [17]. Based on that model, En echelon tensional fractures (T-fracture) and shear fractures were identified [18]. The synthetic shears (R-shears) and antithetic shears (R'-shears) were defined to be Riedel shears [19] [20]. Other secondary structures in a wrench zone include P-shears, Y-shears, and convergent structures like folds and reverse faults [21] [22] [23].

The rejuvenation of preexisting faults can be compared to be transtensional and transpressional wrench. Although there are certain geometric relationships between the fractures and the principal displacement zone in a pure strike-slip [21] [24], there is little analytical discussion on the geometric relationship between the fractures and the pre-existing faults with transtensional and transpressional wrenches [25].

Based on rock failure criterions like the Byerlee's law [26] and Mohr-Coulomb failure criterions [27], this paper discusses the geometric relationships between the transpressional or transtensional pre-existing faults and their related fractures in upper crust where brittle deformation occurs. The results will help to understand wrench related structures both in outcrops and in basins. They can help to the exploration of mineral resources, such as iron, oil and gas. Also, the results will help to analyze structures in a normal fault or a reverse fault.

\section{Methodology}

The pre-existing faults are classified in two types, a hidden one and the other surface one (Figure 2). A stress state is applied to cause their transtensional and transpressional wrenches with a maximum principal stress $\left(\sigma_{1}\right)$ and a minimum stress $\left(\sigma_{3}\right)$. The local induced principal stresses caused by the wrenches of pre-existing faults are $\sigma_{1}^{L}$ and $\sigma_{3}^{L}$. The fault $\mathrm{F}_{1}$ in Figure 2(a) is a hidden pre-existing fault whose rejuvenation after the sedimentation of the layer $\mathrm{L}_{2}$ forms the fault $\mathrm{F}_{2}$. In Figure 2(b), the $\mathrm{F}_{3}$ keeps alive when the sedimentation of

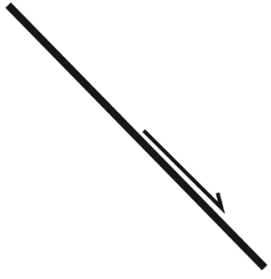

(a)

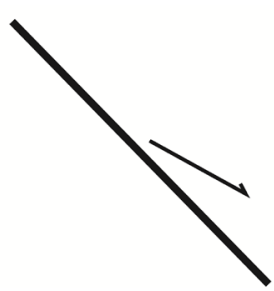

(b)

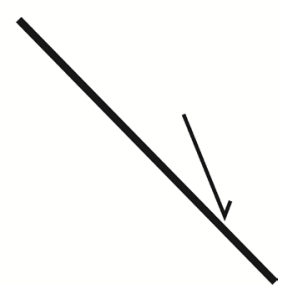

(c)

Figure 1. Types of wrench. (a) parallel, (b) divergent (transtensional), (c) convergent (transpressional). The fault planes are vertical. 


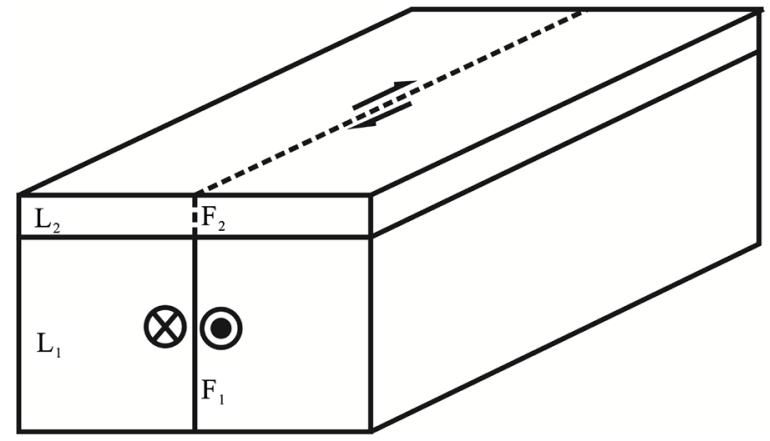

(a)

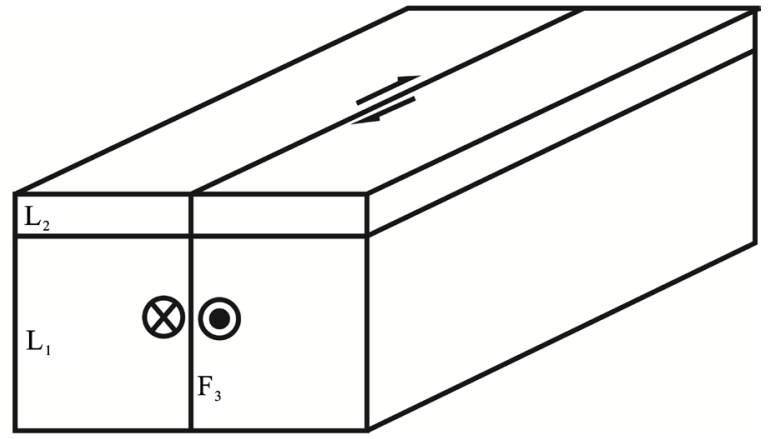

(b)

Figure 2. Two types of pre-existing faults. (a) hidden pre-existing fault $\left(\mathrm{F}_{1}\right)$ with its propagation part of fault $\mathrm{F}_{2}$ after the sedimentation of layer $\mathrm{L}_{2}$, (b) surface pre-existing fault $\left(\mathrm{F}_{3}\right) . \mathrm{L}_{1}$-pre-growth layer, $\mathrm{L}_{2}$-growth layer with identical rock mechanic properties with layer $\mathrm{L}_{1}$.

the layer $\mathrm{L}_{2}$ occurs.

The rock deformation in the upper lithosphere is governed by Coulomb behavior, and the brittle fracture or frictional sliding applies for most the deformation in the upper lithosphere [28] [29]. So, this paper will focus on the discussions on brittle fractures. Typical rock failure criterions include Mohr-Coulomb failure criterion and Byerlee's law [27].

In Mohr-Coulomb failure criterion (Figure 3),

$$
\tau=\tau_{0}+\mu \sigma_{n}=\tau_{0}+\sigma_{n} \tan \psi
$$

$\tau$ is the shear stress with positive sign for counter-clock shear and negative sign for clockwise shear. $\sigma_{n}$ is the normal stress with positive sign for compression and negative sign for extension. $\tau_{0}$ is cohesion. $\mu$ is inner frictional coefficient and $\psi$ is inner frictional angle.

In a transtensional or transpressional pre-existing fault, the normal stress and shear stress on the fault plane are $\sigma_{n}$ and $\tau$ (Figure 3).

$$
\tau=\tau_{f}+\mu \sigma_{n}=\tau_{f}+\sigma_{n} \tan \psi
$$

can be easily derived with Equation (1), in which $\tau_{f}$ is cohesion for the pre-existing fault. Given the layer $L_{1}$ and layer $L_{2}$ having identical rock mechanic properties, the cohesion of the hidden pre-existing fault (Figure 2(a)) can be represented as

$$
\tau_{f}=\frac{h_{2}}{h_{1}+h_{2}} \tau_{0}=K \tau_{0}
$$

where the $h_{1}$ is the thickness of layer $\mathrm{L}_{1}$ and the $h_{2}$ is the thickness of the layer $\mathrm{L}_{2}$ and $K$ is the cohesion coefficient, which also can be considered to be the ratio of the cohesion of a weak fabric to the cohesion of the intact homogenous rock. The Equation (3) is shown in Figure 3. For the surface pre-existing fault (Figure 2(b)), the cohesion is considered to be zero because the fault $\mathrm{F}_{3}$ is a syn-sedimentary fault and the layer $\mathrm{L}_{2}$ is faulted. The Equation (2) becomes to be the Byerlee's law which is

$$
\tau=\mu \sigma_{n}=\sigma_{n} \tan \psi
$$

which equation is shown in Figure 3 as well. 


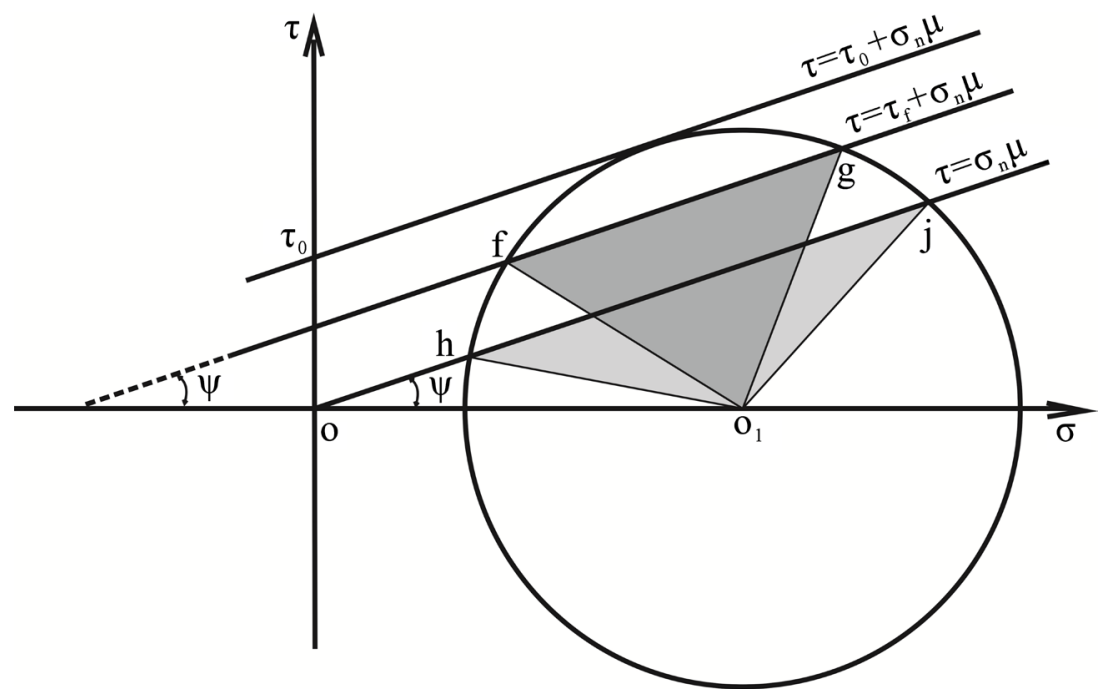

Figure 3. Failure criteria. $\tau_{0}$ is the cohesion of intact rock. $\tau_{f}$ is cohesion of hidden pre-existing fault. $\Psi$ is the inner frictional angle of rock. The triangle $\Delta \mathrm{jo}_{1} \mathrm{~h}$ is the range for surface pre-existing faults with zero cohesion to rejuvenate before new Coulomb fractures occur. The triangle $\Delta \mathrm{go}_{1} \mathrm{f}$ is the range for hidden pre-existing faults with certain cohesion to rejuvenate before new Coulomb fractures occur.

For a pre-existing fault, the stresses on the fault plane are $\sigma_{n}$ and $\tau$. The stress Mohr circle for the local induced $\sigma_{1}^{L}$ and $\sigma_{3}^{L}$ stresses crosses through the points $\left(\sigma_{n}, \tau\right)$ and $(0,-\tau)$. Where the normal stress $\left(\sigma_{n}\right)$ is positive, a transpressional wrench will occur, in which situation the center of the $\sigma_{1}^{L}-\sigma_{3}^{L}$ circle is on the positive part of the $\sigma$ axis. Oppositely, where the normal stress $\left(\sigma_{n}\right)$ is negative, a transtensional wrench will occur. Then the center of the $\sigma_{1}^{L}-\sigma_{3}^{L}$ circle will be on the negative part of the $\sigma$ axis and this would be meaningless in the surface pre-existing fault. Where the normal stress $\left(\sigma_{n}\right)$ is zero, a pure wrench will occur.

\section{A Hidden Pre-Existing Fault}

For a given hidden pre-existing fault with a cohesion of $\tau_{f}$ (Figure 4), it will rejuvenate under the applied stresses of $\sigma_{1}$ and $\sigma_{3}$. Figure $4(\mathrm{a})$ is a pre-existing fault $(\mathrm{PF})$ and its applied stress state while a left-handed transpressional or transtensional wrench occurs. Figure 4(b) shows local induced normal stress and shear stress. Figure 4(c) display Mohr stress circles for applied stress state $\left(\sigma_{1}-\sigma_{3}\right.$ circle $)$ and local induced stress state $\left(\sigma_{1}^{L}-\sigma_{3}^{L}\right.$ circle $)$ in transpressional wrenches. Figure 4(d) shows the geometric relationships between local induced maximum principal stress $\left(\sigma_{1}^{L}\right)$ and the pre-existing fault $(\mathrm{PF})$ in transpressional wrenches. Figure $4(\mathrm{e})$ shows Mohr stress circles for applied stress state $\left(\sigma_{1}-\sigma_{3}\right.$ circle) and local induced stress state $\left(\sigma_{1}^{L}-\sigma_{3}^{L}\right.$ circle) in transtensional wrenches. Figure 4(f) shows the geometric relationships between local induced minimum principal stress $\left(\sigma_{3}^{L}\right)$ and the pre-existing fault $(\mathrm{PF})$ in transtensional wrenches. The $n$ is the normal of the pre-existing fault, the PF the pre-existing fault, the $\psi$ the inner frictional angle, the $\beta$ the axis-fault angle either between the 


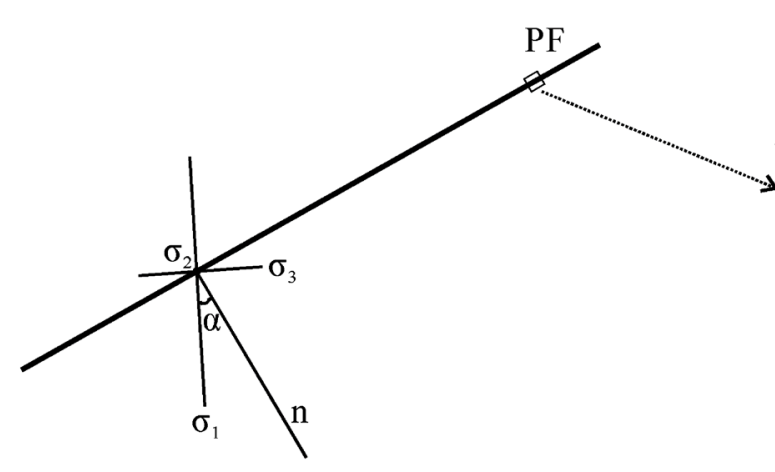

(a)

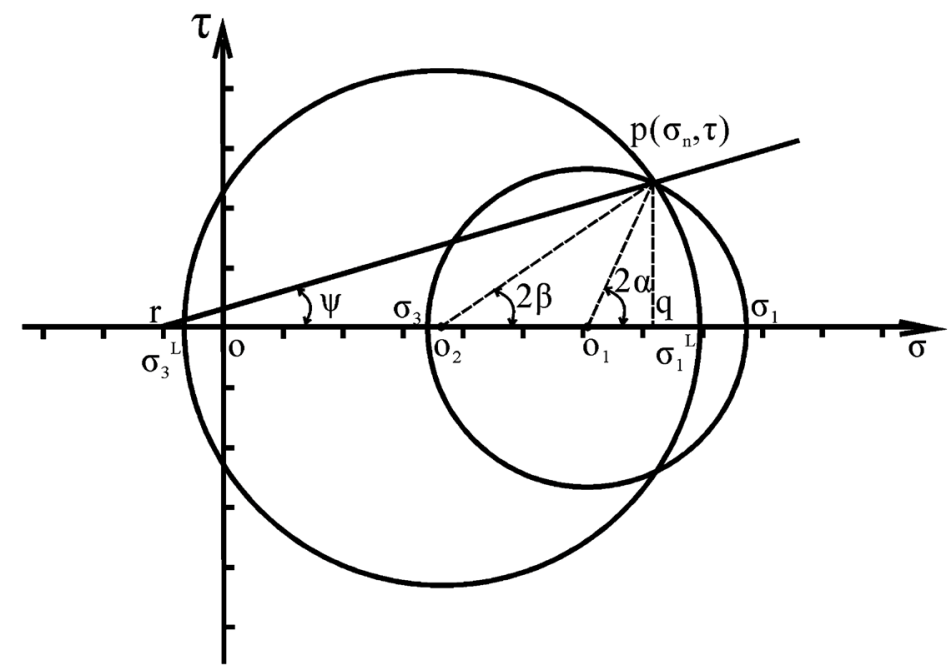

(c)

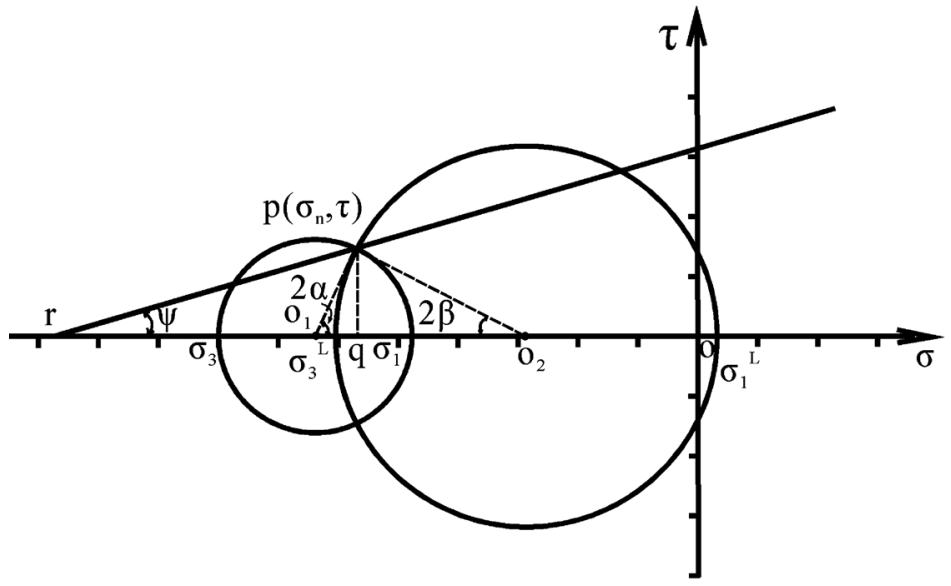

(e)

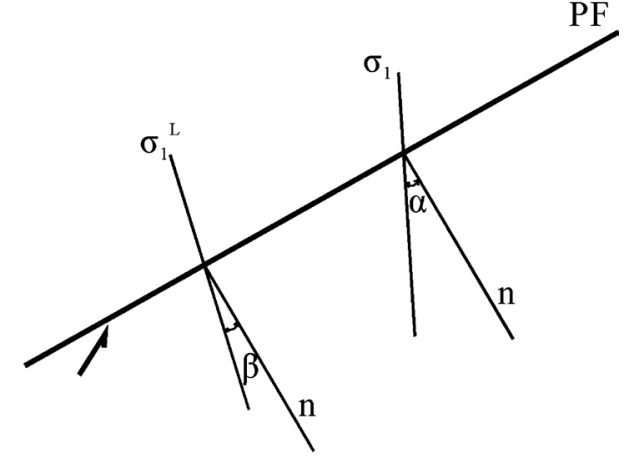

(d)

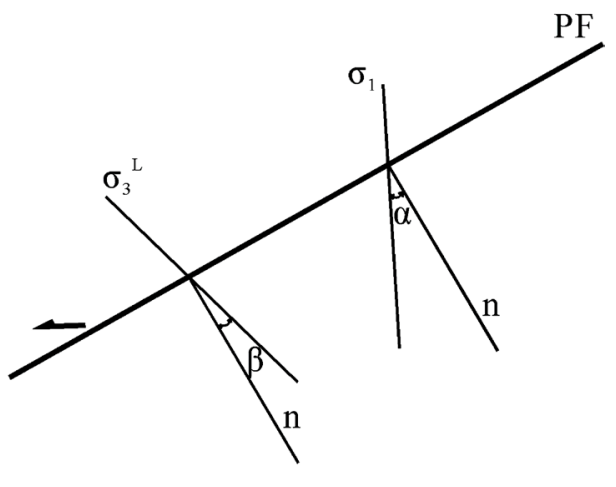

(f)

Figure 4. Direction of local induced principal stress axis around a rejuvenating pre-existing fault. See the text for the meanings of the letters.

local induced maximum principal stress axis $\left(\sigma_{1}^{L}\right)$ and the normal of the PF where transpressional wrench occurs or between the local induced minimum principal stress axis $\left(\sigma_{3}^{L}\right)$ and the normal of the PF where transtensional wrench 
occurs, the $\alpha$ the angle between the maximum principal stress axis $\left(\sigma_{1}\right)$ and the normal of the PF. The $\sigma_{1}-\sigma_{3}$ circle with the circle center of $o_{1}$ is Mohr stress circle for applied maximum and minimum principle stresses $\sigma_{1}$ and $\sigma_{3}$. The $\sigma_{1}^{L}$ \& $\sigma_{3}^{L}$ circle is Mohr stress circle with the circle center of $o_{2}$ for local induced maximum and minimum principle stresses $\sigma_{1}^{L}$ and $\sigma_{3}^{L}$. The $r$ is the intersection of the failure criterion to the abscissa axis. The $p$ is the intersection of the two Mohr stress circles. The $p q$ is perpendicular to the abscissa axis.

If a positive normal stress $\left(\sigma_{n}\right)$ acts on the pre-existing fault, this fault is a left-handed transpressional one. The plane parallel to the fault has a normal stress of $\sigma_{n}$ and a shear stress of $\tau$ (Figure 4(b)). The plane perpendicular to the fault has a normal stress of zaro and a shear stress of $-\tau$ (Figure 4(b)). A Mohr cicle can be gotten crossing the point of $p\left(\sigma_{n}, \tau\right)$ and the point $(0,-\tau)$ (the bigger cicle, Figure $4(\mathrm{c}))$. The local induced principal stresses of $\sigma_{1}^{L}$ and $\sigma_{3}^{L}$ are created. The angle between the $\sigma_{1}^{L}$ and the normal of the pre-existing fault is $\beta$ (Figure 4(d)). In terms of the Figure 4(c), we have

$$
\tan 2 \beta=\left(\frac{\overline{r o}}{\overline{o_{2} q}}+2\right) \tan \psi
$$

where $\beta$ is called the axis-fault angle, being the angle between the local induced maximum principal stress axis $\sigma_{1}^{L}$ and the normal of the pre-existing fault where a transpressional wrench occurs(Figure $4(\mathrm{~d})$ ). The axis-fault $\beta$ is measured clockwise from the normal of the pre-existing fault to the local induced maximum principal stress axis $\sigma_{1}^{L}$ (Figure $4(\mathrm{~d})$ ). The $\overline{r o}$ is the length of the line section $r o$ and the $\overline{O_{2} q}$ is the length of the line section $o_{2} q$.

If a negative normal stress acts on the pre-existing fault, this fault is a left-handed transtensional one (Figure 4(e) and Figure 4(f)). We have

$$
\tan 2 \beta=\left(\frac{\overline{r o}}{\overline{o_{2} q}}-2\right) \tan \psi
$$

where $\beta$ is the angle between the local induced minimum principal stress axis $\sigma_{3}^{L}$ and the normal of the pre-existing fault where a transtensional wrench occurs (Figure 4(e), Figure 4(f)). The axis-fault $\beta$ is measured anticlockwise from the normal of the pre-existing fault to the local induced minimum principal stress axis $\sigma_{3}^{L}$ (Figure 4(f)). The $\overline{r o}$ is the length of the line section ro and the $\overline{o_{2} q}$ is the length of the line section $o_{2} q$.

Integrating Equations (5) and (6), we have

$$
\tan 2 \beta=\left(\frac{\overline{r o}}{\overline{o_{2} q}} \pm 2\right) \tan \psi
$$

A plus sign is adopted for a transpressional wrench and a minus sign is adopted for a transtensional wrench accordingly. It will be noted that the axis-fault $\beta$ is measured clockwise from the normal of the pre-existing fault to the local induced maximum principal stress axis $\sigma_{1}^{L}$ (Figure 4(d)) which in the meantime is measured anticlockwise from the normal of the pre-existing 
fault to the local induced minimum principal stress axis $\sigma_{3}^{L}$ (Figure $4(f)$ ).

Because

$$
\overline{r o}=\frac{\tau_{f}}{\mu}
$$

Then we can substitute Equations (3) and (8) into Equation (7), and we get

$$
\tan 2 \beta=\left(\frac{K \tau_{0}}{\mu \cdot \overline{o_{2} q}} \pm 2\right) \tan \psi=\frac{K \tau_{0}}{\overline{o_{2} q}} \pm 2 \tan \psi
$$

which concludes that the axis-fault angle $(\beta)$ is determined by both the cohesion coefficient $(K)$ and the applied stress state for a given rock layer. The directions of fractures related to those wrenches could be determined based on the Coulomb failure criterion.

\section{A Surface Pre-Existing Fault}

Given a thin growth layer $\mathrm{L}_{2}$ and a large inner frictional coefficient, the cohesion coefficient approximately equals to zero. The Coulomb failure criterion line moves to cross through the coordinate origin o (Figure 6(a)). On a transpressional wrench,

$$
\tan 2 \beta=2 \tan \psi
$$

or

$$
\beta=\frac{\arctan (2 \tan \psi)}{2}
$$

The angle between the local induced maximum principal stress axis and the pre-existing fault is $90-\beta$ (Figure $5(\mathrm{~b})$ ). The angle between the applied maximum principal stress axis and the pre-existing fault is $90-\alpha$.

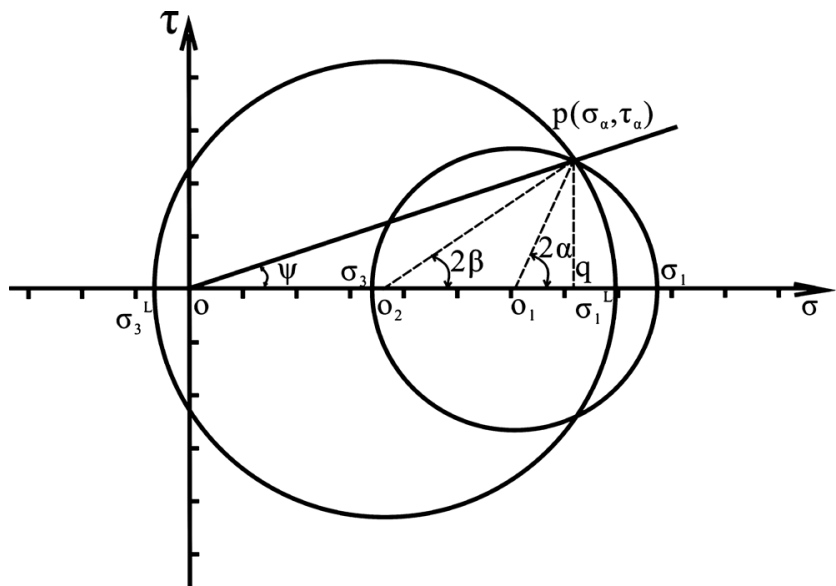

(a)

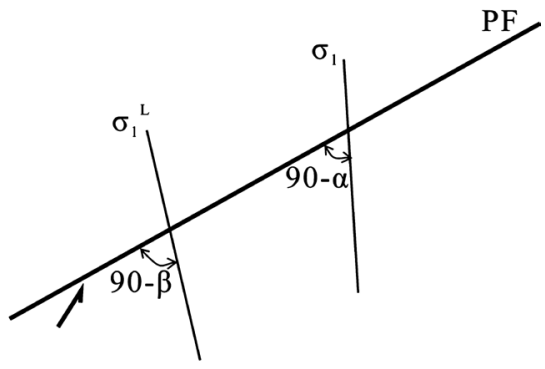

(b)

Figure 5. Stress state in a transpressional wrench fault with a zero cohesion. n-normal of the pre-existing fault, PF-pre-existing fault, $\psi$-inner frictional angle, $\beta$-axis-fault angle between the local induced maximum principal stress axis $\left(\sigma_{1}^{L}\right)$ and the normal of the PF, $\alpha$-angle between the maximum principal stress axis $\left(\sigma_{1}\right)$ and the normal of the PF. 
In terms of Coulomb failure criterion, the geometric relationships of the fractures accompanying the transpressional wrench of the pre-existing fault with zero cohesion to the pre-existing faults are shown in Figure 6(a). The angle between the pre-existing fault and the $\mathrm{R}$ shear would be $45^{\circ}+\psi / 2-\beta$. The angle between the pre-existing fault and the $\mathrm{T}$ fracture would be $90^{\circ}-\beta$. The angle between the pre-existing fault and the $\mathrm{R}^{\prime}$ shear would be $135^{\circ}-\beta-\psi / 2$.

In a parallel wrench, the $\overline{o_{2} q}$ is zero. In terms of the equation (9), the tan $(2 \beta)$ is infinitely great. So the $2 \beta$ is equal to $90^{\circ}$ and the $\beta$ is equal to $45^{\circ}$. This indicates the local induced maximum principal stress axis is $45^{\circ}$ to the pre-existing fault, and the geometric relationships of the fractures to the pre-existing faults are shown in Figure 6(b). Considering all the possible $\mathrm{R}$ shears occurring in transpressional wrenches, the angles between the shears and the pre-existing faults will be within a range from $\psi / 2$ (Figure $6(\mathrm{~b})$ ) to $45^{\circ}+\psi / 2-\beta$ (Figure $6(\mathrm{a}))$. The angles between the possible $\mathrm{R}^{\prime}$ shears and the pre-existing faults will be within a range from $90^{\circ}-\psi / 2$ (Figure 6(b)) to $135^{\circ}-\beta-\psi / 2$ (Figure 6(a)). The angles between the possible $\mathrm{T}$ faults and the pre-existing faults will be within a range from $45^{\circ}$ (Figure $\left.6(\mathrm{~b})\right)$ to $90^{\circ}-\beta$ (Figure 6(a)).

In a transtensional wrench with a zero cohesion, the Equation (9) has no result and the local induced principal stress axes will be in the same direction as the applied principal stress axes for there is no friction along the fault surface. The tensional fractures will be perpendicular to the applied minimum principal stress axis and have no relationships to the pre-existing fault (Figure 6(c)). In a transtensional wrench with some cohesion coefficient, the geometric relationships between the wrench related fractures and the pre-existing weak fabrics are determined by the applied stresses like the Equation (9), and they will not be discussed in detail in this paper.

\section{Conclusions}

There are two kinds of pre-existing faults in the crust, one of which is called

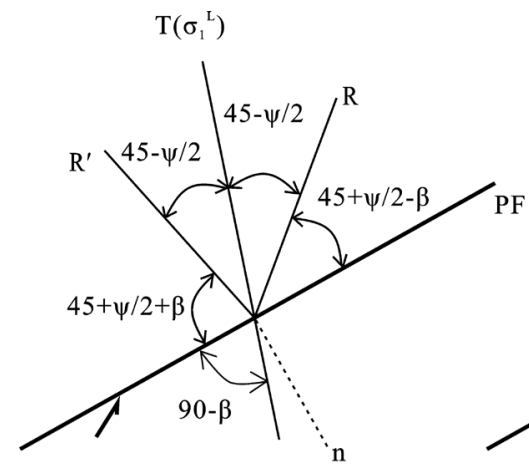

(a)

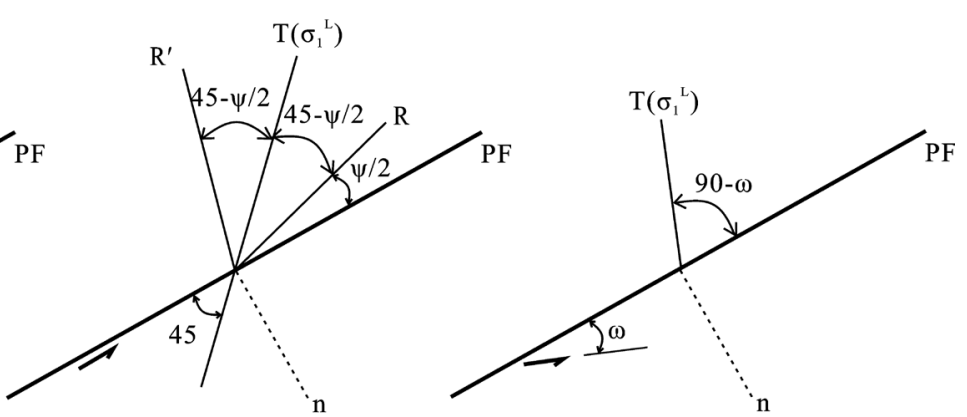

(b) (c)

Figure 6. Comparison among the fractures in various wrench faults with zero cohesion. (a) left-handed transpressional wrench, (b) left-handed parallel wrench, (c) left-handed transtensional wrench with a cohesion of 0 . $\mathrm{R}$ '-antithetic shear, R-synthetic shear, T-tensional fracture, $\omega$-angle between the applied minimum principal stress axis and the pre-existing fault. 
hidden pre-existing faults composed by a buried fault and its overlying sedimentary layer. The other is called surface pre-existing faults with zero cohesion. Quantitative geometric relationships between the pre-existing faults and the fractures related to their transpressional and transtensional wrenches are established based on the Coulomb fracture criterion and Byerlee's frictional law for brittle deformation regimes. These geometric relationships are controlled by both the cohesion coefficients and the applied stresses for a given rock, where the cohesion coefficient refers to the ratio of the thickness of the unfaulted covering layer to the sum thickness of the whole wrench body. This cohesion coefficient can also be understood to be the ratio of a pre-existing weak fabric to an intact homogeneous rock.

For transpressional wrenches of the pre-existing faults, the angles between the $\mathrm{R}$ shears and the pre-existing faults will be within a range from $\psi / 2$ to $45^{\circ}+$ $\psi / 2-\beta$, where the $\psi$ is the rock inner frictional angle and the $\beta$ is the angle between the normal of the pre-existing fault and the local induced principal stress axes. The angles between the possible $\mathrm{R}^{\prime}$ shears and the pre-existing faults will be within a range from $90^{\circ}-\psi / 2$ to $135^{\circ}-\beta-\psi / 2$. The angles between the possible $\mathrm{T}$ faults and the pre-existing faults will be within a range from $45^{\circ}$ to $90^{\circ}-\beta$. For the transtensional wrenches of the pre-existing faults with some cohesion, the geometric relationships of the local induced stresses to the pre-existing fault are determined by the applied stresses. In a surface pre-existing fault without cohesion, there would be no wrench related fracture and the directions of the fractures are determined by the applied stresses. For parallel wrenches, there are certain relationships between the wrench related fractures and the principal displacements.

Although the theoretical geometric relationships between the pre-existing faults and their wrench related fractures are derived based on left handed wrenches, they are of referring significance for right handed wrenches. These theoretical geometric relationships can help to understand and analyze wrench zones both in outcrops and in subsurface like oil bearing areas. They are of important guidance in petroleum exploration. The pre-existing faults can also be considered to pre-existing fabrics, and the cohesion coefficient is the ratio between the cohesion of the pre-existing weak fabric and that of the intact homogenous rock.

\section{Acknowledgements}

This study was jointly funded by the "Mechanism of deep hydrocarbon migration and enrichment in key areas of Sichuan basin" (no.XDA14010306), the "National key research and development plan-"ultra-deep layer, Mesoproterozoic and Neoproterozoic cap sealing property and oil-gas preservation mechanism" (no.2017YFC0603105), the "Development in Large-scale oil-gas field and coalbed methane project"- "Reservoir formation conditions and controlling factors in deep-ultra-deep Cambrian in Tarim basin" (no.2017ZX05005-002-005) and 
the "Quantitative characterization on various types of strike-slip faults in Jiyang depression" (no.30200018-19-ZC0613-0118). The author will thank Zongpeng Chen for his revision of English draft.

\section{Conflicts of Interest}

The author declares no conflicts of interest regarding the publication of this paper.

\section{References}

[1] Lowell, J.D. (1985) Structural Styles in Petroleum Exploration. OGCI Publications, Tulsa.

[2] Chen, S.P., Zhou, X.H., Tang, L.J., Wang, Y.B., Lü, D.Y., Sun, M.S. and Qu, D.M. (2010) Wrench-Related Folding: A Case Study of Bohai Sea Basin, China. Marine and Petroleum Geology, 27, 179-190.

https://doi.org/10.1016/j.marpetgeo.2009.08.004

[3] Faulkner, D.R., Jackson, C.A.L., Lunn, R.J., Schlische, R.W., Shipton, Z.K., Wibberley, C.J. and Withjack, M.O. (2010) A Review of Recent Developments Concerning the Structure, Mechanics and Fluid Flow Properties of Fault Zones. Journal of Structural Geology, 32, 1557-1575. https://doi.org/10.1016/j.jsg.2010.06.009

[4] Tavani, S., Quintà, A. and Granado, P. (2011) Cenozoic Right-Lateral Wrench Tectonics in the Western Pyrenees (Spain): The Ubierna Fault System. Tectonophysics, 509, 238-253. https://doi.org/10.1016/j.tecto.2011.06.013

[5] Allen, P.A. and Allen, J.R. (2013) Basin Analysis: Principles and Application to Petroleum Play Assessment. Third Edition, Wiley and Blackwell, Hoboken.

[6] Babaahmadi, A. and Rosenbaum, G. (2014) Late Mesozoic and Cenozoic Wrench Tectonics in Eastern Australia: Insights from the North Pine Fault System (Southeast Queensland). Journal of Geodynamics, 73, 83-99.

https://doi.org/10.1016/j.jog.2013.10.001

[7] Alsop, G.I., Weinberger, R., Marco, S. and Levi, T. (2018) Fault and Fracture Patterns around a Strike-Slip Influenced Salt Wall. Journal of Structural Geology, 106, 103-124. https://doi.org/10.1016/j.jsg.2017.10.010

[8] Anderson, H., Walsh, J.J. and Cooper, M.R. (2018) The Development of a Regional-Scale Intraplate Strike-Slip Fault System: Alpine Deformation in the North of Ireland. Journal of Structural Geology, 116, 47-63.

https://doi.org/10.1016/j.jsg.2018.07.002

[9] Belferman, M., Katsman, R. and Agnon, A. (2018) Effect of Large-Scale Surface Water Level Fluctuations on Earthquake Recurrence Interval under Strike-Slip Faulting. Tectonophysics, 744, 390-402. https://doi.org/10.1016/j.tecto.2018.06.004

[10] Chen, S.P., Xu, S.S., Cai, Y. and Ma, X.D. (2018) Wrench Related Faults and Their Control on the Tectonics and Eocene Sedimentation in the L13-L15 Sub-Sag Area, Pearl River Mouth Basin, China. Marine Geophysical Research, 39, 363-381. https://doi.org/10.1007/s11001-017-9328-1

[11] Ghamrya, M.N.E., Amawyb, M.E. and Hagagb, W. (2020) The Role of Late Cretaceous Wrench Tectonics in Hydrocarbon Endowment in El-Gindi Basin, Northern Western Desert, Egypt. Marine and Petroleum Geology, 112, 1-14. https://doi.org/10.1016/j.marpetgeo.2019.104093

[12] Morley, C.K., Haranya, C., Phoosongsee, W., Pongwapee, S., Kornsawan, A. and 
Wonganan, N. (2004) Activation of Rift Oblique and Rift Parallel Pre-Existing Fabrics during Extension and their Effect on Deformation Style: Examples from the Rifts of Thailand. Journal of Structural Geology, 26, 1803-1829.

[13] Mouslopoulou, V., Nicol, A., Little, T.A. and Walsh, J.J. (2007) Displacement Transfer between Intersecting Regional Strike-Slip and Extensional Fault Systems. Journal of Structural Geology, 29, 100-116. https://doi.org/10.1016/j.jsg.2006.08.002

[14] Wu, G.H., Yuan, Y.J., Huang, S.Y., Vandyk, T.M., Xiao, Y., Cai, Q. and Luo, B.X. (2018) The Dihedral Angle and Intersection Processes of a Conjugate Strike-Slip Fault System in the Tarim Basin, NW China. Acta Geologica Sinica, 92, 74-88. https://doi.org/10.1111/1755-6724.13495

[15] Wu, G.H., Zhao, K.Z., Qu, H.Z., Scarselli, N. and Xu, Y.F. (2020) Permeability Distribution and Scaling in Multi-Stages Carbonate Damage Zones: Insight from Strike-Slip Fault Zones in the Tarim Basin, NW China. Marine and Petroleum Geology, 114, Article ID: 104208. https://doi.org/10.1016/j.marpetgeo.2019.104208

[16] Mathieu, L., de Vries, W., Pilato, M. and Troll, V.R. (2011) The Interaction between Volcanoes and Strike-Slip, Transtensional and Transpressional Fault Zones: Analogue Models and Natural Examples. Journal of Structural Geology, 33, 898-906. https://doi.org/10.1016/j.jsg.2011.03.003

[17] Cloos, H. (1928) Exiperimente zur inneren Tectonik: Zentralblatt fur Mineralogie. Geologie und Paleontologie, 12b, 609-621.

[18] Riedel, W. (1929) Zur mechanik geologischer brucherscheinungen. Zentralblatt fur Mineralogie. Geologie und Paleontologie B, 354-368.

[19] Hills, E.S. (1963) Elements of Structural Geology. Methuen \& Co. Ltd., London.

[20] Skempton, A.W. (1966) Some Observations on Tectonic Shear Zones. Proceedings of 1 st International Congress on Rock Mechanics, Vol. 1, Lisbon, 329-335.

[21] Harding, T.P. (1974) Petroleum Traps Associated with Wrench Faults. AAPG Bulletin, 58, 1290-1304. https://doi.org/10.1306/83D91669-16C7-11D7-8645000102C1865D

[22] Schreurs, G. (1994) Experiments on Strike-Slip Faulting and Block Rotation. Geology, 22, 567-570. https://doi.org/10.1130/0091-7613(1994)022<0567:EOSSFA >2.3.CO;2

[23] Xu, S.S., Peng, H., Angel, F., Nieto-Samaniego, Chen, S.P. and Wu, X.D. (2017) The Similarity between Riedel Shear Patterns and Strike-Slip Basin Patterns. Geological Review, 63, 287-300.

[24] Chen, S.P. (2020) On the Occurrences of Fractures in Wrench Zones. World Journal of Mechanics, 10, 27-38. https://doi.org/10.4236/wjm.2020.103003

[25] Sanderson, D.J. and Marchini, W.R. (1984) Transpression. Journal of Structural Geology, 6, 449-458. https://doi.org/10.1016/0191-8141(84)90058-0

[26] Byerlee, J. (1978) Friction of Rocks. Pure and Applied Geophysics, 116, 615-626. https://doi.org/10.1007/BF00876528

[27] Kohlstedt, D.L., Evans, B. and Mackwell, S.J. (1995) Strength of the Lithosphere: Constraints Imposed by Laboratory Experiments. Journal of Geophysical Research, 100, 17587-17602. https://doi.org/10.1029/95JB01460

[28] Davis, D., Suppe, J. and Dahlen, F.A. (1983) Mechanics of Fold-and-Thrust Belts and Accretionary Wedges. Journal of Geophysical Research, 88, 1153-1172. https://doi.org/10.1029/JB088iB02p01153

[29] Xiao, H. and Suppe, J. (1991) Mechanics of Extensional Wedges. Journal of Geophysical Research, 96, 10301-10318. https://doi.org/10.1029/91JB00222 